\title{
Risk factors for mechanical ventilation and reintubation after pediatric heart surgery
}

\author{
Punkaj Gupta, MBBS, ${ }^{a}$ Mallikarjuna Rettiganti, PhD, ${ }^{b}$ Jeffrey M. Gossett, MS, ${ }^{b}$ Justin C. Yeh, MD, ${ }^{c}$
} Howard E. Jeffries, MD, MBA, ${ }^{\mathrm{d}, \mathrm{e}}$ Tom B. Rice, MD, ${ }^{\mathrm{e}, \mathrm{f}}$ and Randall C. Wetzel, MBBS ${ }^{\mathrm{e}, \mathrm{g}}$

\section{ABSTRACT}

Objective: To determine the prevalence of and risk factors associated with the need for mechanical ventilation in children following cardiac surgery and the need for subsequent reintubation after the initial extubation attempt.

Methods: Patients younger than 18 years who underwent cardiac operations for congenital heart disease at one of the participating pediatric intensive care units (ICUs) in the Virtual PICU Systems (VPS), LLC, database were included (2009-2014). Multivariable logistic regression models were fitted to identify factors likely associated with mechanical ventilation and reintubation.

Results: A total of 27,398 patients from 62 centers were included. Of these, 6810 patients $(25 \%)$ were extubated in the operating room (OR), whereas 20,588 patients $(75 \%)$ arrived intubated in the ICU. Of the patients who were extubated in the OR, 395 patients $(6 \%)$ required reintubation. In contrast, 2054 patients $(10 \%)$ required reintubation among the patients arriving intubated postoperatively in the ICU. In adjusted models, patient characteristics, patients undergoing high-complexity operations, and patients undergoing operations in lower-volume centers were associated with higher likelihood for the need for postoperative mechanical ventilation and need for reintubation. Furthermore, the prevalence of mechanical ventilation and reintubation was lower among the centers with a dedicated cardiac ICU in propensity-matched analysis among centers with and without a dedicated cardiac ICU.

Conclusions: This multicenter study suggests that proportion of patients extubated in the OR after heart operation is low. These data further suggest that extubation in the OR can be done successfully with a low complication rate. (J Thorac Cardiovasc Surg 2016;151:451-8)

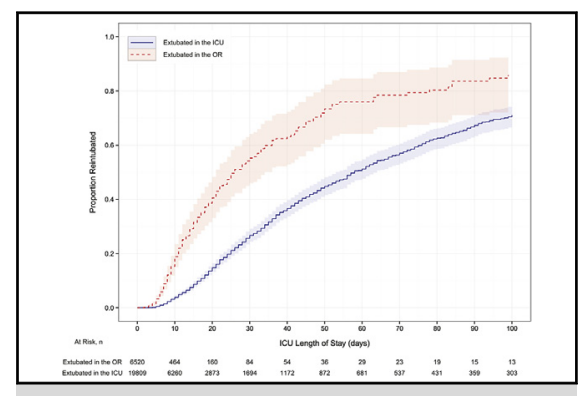

Prevalence of reintubation with increasing length of ICU stay among the study patients.

\section{Central Message}

Although the prevalence of extubation in the operating room is low, it is associated with low complication rate.

\section{Perspective}

Our data suggest that both odds of mechanical ventilation and odds of reintubation following pediatric cardiac surgery are a function of patient characteristics, surgical risk category, center volume, and presence of a dedicated cardiac ICU. We also demonstrated that approximately one-quarter of patients are extubated in the operating room with low rate of reintubation and low mortality.

See Editorial Commentary page 458.

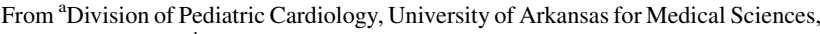
Little Rock, Ark; ${ }^{\mathrm{b}}$ Division of Biostatistics, Department of Pediatrics, University of Arkansas for Medical Sciences, Little Rock, Ark; ${ }^{\mathrm{C}}$ Division of Cardiology, Department of Pediatrics, Rady Children's Hospital, San Diego, Calif; ' Division of Pediatric Critical Care, Department of Pediatrics, Seattle Children's Hospital, University of Washington School of Medicine, Seattle, Wash; ${ }^{e}$ Virtual PICU Systems, LLC, Los Angeles, Calif; ${ }^{\mathrm{f}}$ Division of Critical Care Medicine, Department of Pediatrics, Medical College of Wisconsin, Milwaukee, Wis; and ${ }^{g}$ Division of Critical Care Medicine, Department of Pediatrics and Anesthesiology, Children's Hospital Los Angeles, USC Keck School of Medicine, Los Angeles, Calif.

Data were provided by Virtual PICU Systems, LLC. No endorsement or editorial restriction of the interpretation of these data or opinions of the authors has been implied or stated.

Received for publication April 29, 2015; revisions received Sept 8, 2015; accepted for publication Sept 12, 2015; available ahead of print Oct 24, 2015.

Address for reprints: Punkaj Gupta, MBBS, University of Arkansas for Medical Sciences, College of Medicine, Arkansas Children's Hospital, 1 Children's Way, Slot 512-3, Little Rock, AR 72223 (E-mail: pgupta2@uams.edu). $0022-5223 / \$ 36.00$

Copyright (c) 2016 by The American Association for Thoracic Surgery http://dx.doi.org/10.1016/j.jtcvs.2015.09.080
}

丹 Supplemental material is available online.

Although the postoperative management of children undergoing heart surgery has changed significantly over the years, the concept of early extubation in the operating room (OR) after heart surgery is still in evolution. Some institutions extubate even the most vulnerable patients in the OR after their cardiac surgery. ${ }^{1-5}$ Others continue mechanical ventilation (MV) postoperatively in the intensive care unit (ICU) due to risks associated with untimely extubation. ${ }^{6-8}$ Identifying which children can be successfully removed from $\mathrm{MV}$ in the OR after cardiac surgery is a complex decision process. Research that 


\section{Abbreviations and Acronyms \\ $\mathrm{CPB}=$ cardiopulmonary bypass \\ ECMO = extracorporeal membrane oxygenation \\ ICU = intensive care unit \\ MV = mechanical ventilation \\ OR $\quad=$ operating room \\ PIM $\quad=$ Pediatric Index of Mortality \\ PRISM = Pediatric Risk of Mortality \\ STS-EACTS $=$ Society of Thoracic Surgeons- \\ European Association for \\ Cardiothoracic Surgery}

unravels the factors contributing to the risk of extubation failure could affect outcomes and reduce costs.

Previous studies evaluating early extubation (and success associated with early extubation) consisted primarily of single-center reports in selected patient populations. ${ }^{1-5}$ Some of these studies excluded young patients, patients undergoing complex surgical repair, and patients requiring prolonged cardiopulmonary bypass a priori from their study population. ${ }^{9}$ For this reason, there is limited information in a multi-institutional patient population involving children with varying surgical complexity and across centers with varied surgical volume.

To address these knowledge gaps, this study was designed to evaluate the prevalence of and risk factors associated with the need for MV following cardiac surgery in a large, multi-institutional patient population using the Virtual PICU Systems, LLC (VPS) database, a pediatric critical care network of a diverse set of hospitals caring for critically ill children. A secondary aim of this study was to evaluate the prevalence of and risk factors for reintubation after the initial extubation attempt either in the OR or in the ICU.

\section{MATERIALS AND METHODS Data Source}

The VPS is an online pediatric critical care network formed by NACHRI (National Association of Children's Hospitals and Related Institutions, now part of Children's Hospital Association), Children's Hospital Los Angeles, and Children's Hospital of Wisconsin to develop a Web-based database with prospective data collection using standardized clinical data definitions, data quality control, and data analysis. The VPS database is a prospective observational cohort of consecutive pediatric ICU (PICU) admissions from a diverse set of hospitals caring for children in the United States. Data are collected and entered by trained individuals. VPS performs initial and quarterly interrater reliability (IRR) testing. The IRR concordance in the VPS database is consistently above $95 \%$. Extensive quality validation is performed by VPS staff before release of the data for analysis. To participate in the VPS database, the individual institutions require institutional review board (IRB) approval. The University of Arkansas for Medical Sciences IRB for the protection of human subjects reviewed the study protocol that involves querying de-identified patient data and determined that it does not fall under the jurisdiction of the IRB review process.

\section{Patient Population}

This analysis focused on 5 years (2009-2014) of de-identified data available in the VPS database. Patients younger than 18 years who underwent operations (with or without cardiopulmonary bypass) for congenital heart disease at one of the participating PICUs in the VPS database were included. Cases were classified on the basis of the first cardiovascular operation of each hospital admission (the index operation). The resultant patient population included 40,903 patients from 64 centers. Patients undergoing surgical closure of an isolated patent ductus arteriosus $(n=360)$, and patients with no documented index operation $(n=4224)$ were excluded from the study population. Patients whose operation was not classified into one of the Society of Thoracic Surgeons-European Association for Cardiothoracic Surgery (STS-EACTS) Mortality Categories (category 1 , lowest mortality risk; category 5 , highest mortality risk) $(\mathrm{n}=8921)$ were also excluded. ${ }^{10}$ The study exclusions applied in our study were similar to other studies in pediatric cardiac surgical population from STS database. ${ }^{11,12}$ The final study population therefore included 27,398 patients from 62 centers (Figure 1).

For study purposes, the study population was divided into 2 groups: patients extubated in the OR, and patients arriving intubated in the ICU. Reintubation was defined as need for MV after initial extubation attempt either in the OR or in the ICU during the same hospital stay. Data on demographics, patient diagnoses, conventional MV, severity of illness scores, and outcomes were collected. Specific demographic and severity of illness data included age, gender, developmental disorder, failure to thrive, genetic disorder, low birth weight, Pediatric Index of Mortality 2 (PIM-2) score, ${ }^{13}$ and Pediatric Risk of Mortality III (PRISM III) score. ${ }^{14}$ Data were also collected on the use of cardiopulmonary bypass (CPB) pump during the cardiac surgery, use of extracorporeal membrane oxygenation (ECMO) after cardiac surgery, heart transplantation, ICU length of stay, and ICU mortality. Patients were grouped into 2 surgical risk categories on the basis of the 5 STS-EACTS Mortality categories (with categories 1, 2, and 3 classified as "low" risk and categories 4 and 5 classified as "high" risk). ${ }^{10,11}$ Patients receiving orthotopic heart transplantation with or without congenital heart surgery were classified in the heart transplantation category. Center characteristics were also collected, including presence of dedicated cardiovascular ICU, annual discharges per center, and annual cardiac surgery cases per year.

\section{Statistical Analysis}

Descriptive statistics were expressed as median (first quartile, third quartile) for continuous variables, and percentage (frequency) for categorical variables. The distributions of continuous variables of 2 groups (with and without MV) were compared by using the Kruskal-Wallis tests, whereas the proportions of categorical variables were compared using a $\chi^{2}$ test. Multivariable mixed effects logistic regression models were fitted to identify factors likely associated with MV and reintubation (both binary outcomes) after adjustment for other risk factors. Model goodness-of-fit was assessed by using the ratio of the generalized $\chi^{2}$ statistic to its degrees of freedom and its discriminative ability was measured using the C-statistic.

We used bootstrap bagging to identify factors associated with each of the 2 outcomes. We generated 199 bootstrap samples of the dataset with replacement from the original data and fit multivariable models on each of these simulated datasets. The bootstrap estimates of the odds ratios were obtained by aggregating (mean) the estimates obtained from these 199 bootstrap samples. The $95 \%$ bootstrap confidence intervals for the odds ratios were obtained by obtaining the 2.5 th and the 97.5 th percentiles of the bootstrap distribution. ${ }^{15}$

All predictor variables were checked for multicollinearity. PRISM III was significantly correlated with PIM 2 score $(r=0.42, P<.0001)$, and was therefore not included in the model. Heart transplant, arrhythmia, cardiac bypass (associated with high complexity cases, $P<.0001$ ), developmental disorder, and failure to thrive (associated with genetic 


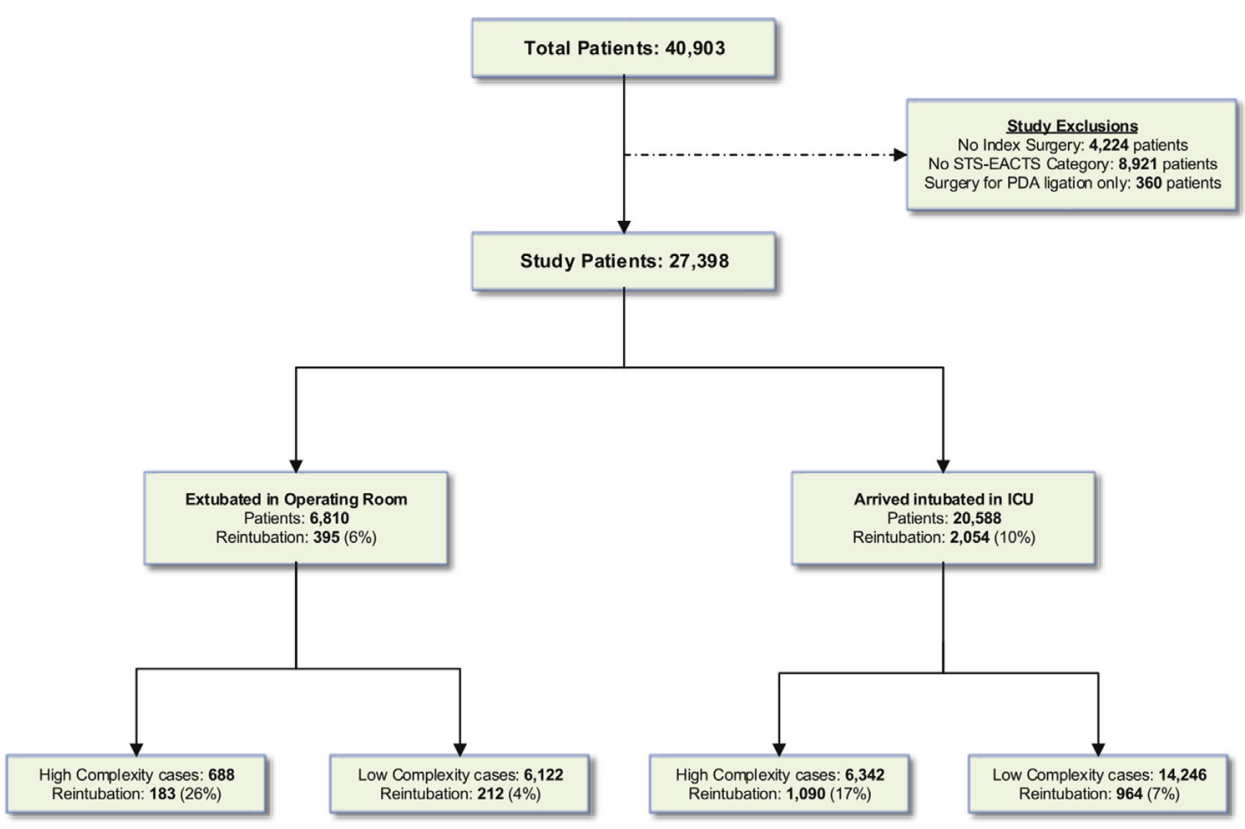

FIGURE 1. Study population. STS-EACTS, Society of Thoracic Surgeons-European Association for Cardiothoracic Surgery; PDA, patent ductus arteriosus; $I C U$, intensive care unit.

syndrome, $P<.0001$ ) were thus not included in either of the multivariable models. The final model for MV included the following patient-specific variables: age at surgery (months), gender (male/female), weight-for-age $z$-score, PIM-2 score, low birth weight, genetic syndrome, highcomplexity cases, acute lung injury, pulmonary hypertension, and more than one surgery. In addition to these variables, the model for reintubation included duration of first MV (days), high-frequency oscillatory ventilation, ECMO, cardiac arrest, chylothorax, diaphragm, renal failure, seizures, sepsis, and brain hemorrhage. Presence of a dedicated cardiac ICU and average annual cardiac surgery cases per center were the 2 center-specific variables included in both the models. Restricted cubic splines were used to model all continuous variables to allow for nonlinear association of the variable on the log odds of the outcome. A generalized estimating equations type analysis was performed to take into account the clustering of patients into different centers.

We compared incidence of MV and reintubation among patients with and without a dedicated cardiac ICU by using propensity score matching. First the probability of a patient being seen in a center with a dedicated cardiac ICU was obtained by using a logistic regression model as a function of patient- and center-level risk factors used in the multivariable models discussed. Then, each patient in the dedicated cardiac ICU group was 1:1 matched with a patient in the no cardiac ICU group based on the logit of the propensity score. The caliper used in the matching was chosen such that all variables used in the matching process were balanced between the 2 groups (standardized difference of 0.10 or less). ${ }^{16}$ Incidence of MV and reintubation were compared between the 2 matched groups using the McNemar test for paired dichotomous outcomes. Statistical software used for analysis included R 3.0.2 (R Foundation for Statistical Computing, Vienna, Austria) and SAS 9.4 (SAS Institute, Inc, Cary, NC). All tests were 2-sided assuming a significance level of $5 \%$.

\section{RESULTS}

A total of 27,398 patients from 62 centers were included. Of these, 6810 patients $(25 \%)$ were extubated in the OR, whereas 20,588 patients $(75 \%)$ arrived intubated in the
ICU after their heart operation. The median duration of MV among children arriving intubated in the ICU was 2 days (interquartile range [IQR] 1-5). Overall mortality for the study population was 743 patients ( $3 \%$ ). Most study patients were located in a dedicated cardiac ICU $(61 \%$, 16,767 patients). The annual center volume for the study population was 152 cardiac surgery cases per center (IQR 47-299).

Of the study patients, $2449(9 \%)$ required reintubation after the initial extubation attempt either in the OR or in the ICU during the same hospital stay. The median time to reintubation was 1 day (IQR 0-3) after the initial extubation attempt. Of the 6810 patients extubated in the OR, $395(6 \%)$ required reintubation in the ICU. In contrast, 2054 patients $(10 \%)$ required reintubation among the remaining 20,588 patients requiring MV postoperatively in the ICU. The incidence of reintubation was higher among patients undergoing highcomplexity operations compared with patients undergoing low-complexity operations $(18 \%$ vs $6 \%, P<.0001)$ (Figure 1). The median ICU length of stay in children requiring reintubation was 22 days (IQR 11-47) compared with 4 days (IQR 3-8) among patients not requiring reintubation during their hospital stay. The mortality was higher among patients requiring reintubation compared with patients who were not reintubated during their hospital stay $(11 \%$ vs $2 \%)$. The proportion of patients reintubated increased with increasing ICU length of stay (Figure 2).

Patient characteristics, center data, and unadjusted outcomes among the patients extubated in the OR and patients arriving intubated in the ICU are displayed in Table 1. Patients who arrived intubated in the ICU were 




FIGURE 2. Prevalence of reintubation with increasing length of ICU stay among the study patients. ICU, Intensive care unit; $O R$, operating room.

younger, smaller, more likely to have preoperative risk factors, and had a higher PIM-2 score and a higher PRISM III score. Patients arriving intubated in the ICU underwent more complex operations, and were associated with higher need for reoperation and increased use of ECMO after cardiac surgery. Patients needing intubation after cardiac surgery were associated with higher incidence of acute lung injury, pulmonary hypertension, cardiac arrest, chylothorax, diaphragm paralysis, seizures, and sepsis. The unadjusted mortality was higher among patients arriving intubated in the ICU compared with patients extubated in the OR.

Table 2 demonstrates the prevalence of MV and reintubation among the patients extubated in the OR and patients arriving intubated in the ICU for 8 STS benchmark operations. The highest prevalence of extubation in the OR was among the patients undergoing Fontan operation and ventricular septal defect (VSD) closure. The highest prevalence of reintubation was noted among the patients undergoing the Norwood operation and truncus arteriosus repair.

After adjusting for patient characteristics, surgical complexity, and center volume, independent risk factors associated with need for MV included younger age, lower weight-for-age $z$-score, low birth weight, presence of genetic disorder, pulmonary hypertension, having received operations of higher complexity, need for reoperation, acute lung injury, higher PIM-2 score, and presence of a dedicated cardiac ICU (Table 3). Independent risk factors associated with the need for reintubation after initial extubation included younger age, lower weightfor-age $z$-score, presence of genetic disorder, pulmonary hypertension, having received operations of higher complexity, need for reoperation, acute lung injury, higher PIM-2 score, presence of postoperative complications (such as cardiac arrest, chylothorax, diaphragm paralysis, seizures, sepsis), use of high-frequency oscillatory ventilation, use of ECMO, extubation in the OR, longer duration of MV before initial extubation, and presence of a dedicated cardiac ICU (Table 4). The ratio of the generalized $\chi^{2}$ statistic and its degrees of freedom were 1.28 and 0.90 respectively for the 2 models predicting MV and reintubation. The C-statistic for the 2 generalized linear mixed effects regression models were 0.89 and 0.84 , respectively, indicating very good discriminative and predictive ability for the model.

Furthermore, we evaluated the association of a dedicated cardiac ICU with need for MV and need for reintubation. Propensity models for the need for MV and need for reintubation are depicted in Tables E1 and E2. In matched sample, the prevalence of MV and reintubation was lower among the centers with a dedicated cardiac ICU (cardiac ICU vs other ICU, MV: $78 \%$ vs $88 \%$, reintubation: $7 \%$ vs $10 \%$ ) (Table E3).

\section{DISCUSSION}

Data from this large, multicenter study establish that approximately one-quarter of patients undergoing 
TABLE 1. Patient characteristics

\begin{tabular}{|c|c|c|c|c|}
\hline Variable & Number of observations & Extubated in OR $(n=6810)$ & Arrived intubated in ICU $(n=20,588)$ & $P$ value \\
\hline \multicolumn{5}{|l|}{ Baseline characteristics } \\
\hline Age at surgery $(\mathrm{mo})$ & 27,398 & $41.3(9.0,96.4)$ & $5.3(0.7,29.7)$ & $<.001$ \\
\hline Male gender & 27,398 & $3697(54.3 \%)$ & $11,399(55.4 \%)$ & .12 \\
\hline Weight-for-age $Z$-score & 27,046 & $-0.6(-1.5,0.3)$ & $-1.1(-2.0,0.1)$ & $<.001$ \\
\hline Developmental disorder & 27,396 & $258(3.8 \%)$ & $528(2.6 \%)$ & $<.001$ \\
\hline Failure to thrive & 27,396 & $469(6.9 \%)$ & $1971(9.6 \%)$ & $<.001$ \\
\hline Genetic disorder & 27,396 & $905(13.3 \%)$ & $4040(19.6 \%)$ & $<.001$ \\
\hline Low birth weight & 27,396 & $155(2.3 \%)$ & $1281(6.2 \%)$ & $<.001$ \\
\hline PIM-2 score & 27,398 & $-5.3(-5.7,4.4)$ & $-3.7(-4.2,-2.9)$ & $<.001$ \\
\hline PRISM III score & 25,106 & $5(2,8)$ & $7(3,10)$ & $<.001$ \\
\hline Use of HFOV & 27,398 & $10(0.1 \%)$ & $178(0.9 \%)$ & $<.001$ \\
\hline \multicolumn{5}{|l|}{ Operation details } \\
\hline $\mathrm{CPB}$ case & 27,398 & $4908(72.1 \%)$ & $13,869(67.4 \%)$ & $<.001$ \\
\hline Need for reoperation & 27,398 & $259(3.8 \%)$ & $3536(17.2 \%)$ & $<.001$ \\
\hline Use of ECMO & 27,398 & $49(0.7 \%)$ & $919(4.5 \%)$ & $<.001$ \\
\hline Heart transplantation & 27,398 & $96(1.4 \%)$ & $404(2 \%)$ & $<.001$ \\
\hline STS-EACTS surgical risk category & 27,398 & & & \\
\hline 1 & & $3395(49.9 \%)$ & $5986(29.1 \%)$ & \\
\hline 2 & & $2308(33.9 \%)$ & $5270(25.6 \%)$ & \\
\hline 3 & & $419(6.2 \%)$ & $2990(14.5 \%)$ & \\
\hline 4 & & $629(9.2 \%)$ & $5082(24.7 \%)$ & \\
\hline 5 & & $59(0.9 \%)$ & $1260(6.1 \%)$ & \\
\hline \multicolumn{5}{|l|}{ Diagnoses } \\
\hline Arrhythmias & 27,396 & $1335(19.6 \%)$ & $3268(15.9 \%)$ & $<.001$ \\
\hline Acute lung injury & 27,396 & $859(12.6 \%)$ & $6813(33.1 \%)$ & $<.001$ \\
\hline Pulmonary hypertension & 27,396 & $131(1.9 \%)$ & $1265(6.1 \%)$ & $<.001$ \\
\hline Cardiac arrest & 27,396 & $55(0.8 \%)$ & $631(3.1 \%)$ & $<.001$ \\
\hline Chylothorax & 27,396 & $42(0.6 \%)$ & $301(1.5 \%)$ & $<.001$ \\
\hline Diaphragm paralysis & 27,396 & $95(1.4 \%)$ & $495(2.4 \%)$ & $<.001$ \\
\hline Use of hemodialysis catheter & 27,398 & $10(0.1 \%)$ & $84(0.4 \%)$ & $<.001$ \\
\hline Renal failure & 27,396 & $57(0.8 \%)$ & $748(3.6 \%)$ & $<.001$ \\
\hline Seizures & 27,396 & $160(2.4 \%)$ & $586(2.8 \%)$ & .02 \\
\hline Sepsis & 27,396 & $26(0.4 \%)$ & $256(1.2 \%)$ & $<.001$ \\
\hline Brain hemorrhage & 27,396 & $13(0.2 \%)$ & $116(0.6 \%)$ & $<.001$ \\
\hline \multicolumn{5}{|l|}{ Unadjusted outcomes } \\
\hline ICU mortality & 27,398 & $44(0.6 \%)$ & $699(3.4 \%)$ & $<.001$ \\
\hline ICU length of stay & 27,398 & $3(2,5)$ & $6(3,12)$ & $<.001$ \\
\hline Center data & & & & $<.001$ \\
\hline Dedicated cardiac ICU & 27,398 & $4706(69.1 \%)$ & $12,061(58.6 \%)$ & $<.001$ \\
\hline Annual cardiac surgery per center & 27,397 & $309(211,571)$ & $295(185,525)$ & $<.001$ \\
\hline
\end{tabular}

Continuous variables are summarized by the triplet of quartiles 50th (25th, 75th). Categorical variables are summarized as n (\%). OR, Operating room; $I C U$, intensive care unit; PIM, Pediatric Index of Mortality; PRISM, Pediatric Risk of Mortality; HFOV, high-frequency oscillatory ventilation; CPB, cardiopulmonary bypass; ECMO, extracorporeal membrane oxygenation; STS-EACTS, Society of Thoracic Surgeons-European Association for Cardiothoracic Surgery.

heart operations are extubated in the OR, whereas approximately three-quarters of patients arrive intubated postoperatively in the ICU. In addition, approximately $9 \%$ of patients require reintubation after their initial extubation attempt. These data suggest that both odds of MV, and odds of reintubation after cardiac surgery are a function of patient characteristics, surgical risk category, and center volume. Furthermore, we demonstrated that patients arriving intubated in the ICU after cardiac surgery are associated with increased ICU mortality and increased ICU length of stay.
Although the ideal approach for patients undergoing cardiac surgery should be extubation in the OR, this approach may be associated with some grave consequences. ${ }^{1,2}$ Some of these consequences include significant hemodynamic instability, sudden cardiac arrest, massive catecholamine surge, and pulmonary hypertensive crisis, unnecessary airway trauma, increased risk for nosocomial infections, and prolonged duration of MV and ICU length of stay. ${ }^{6-8,17,18}$ Our study, therefore, identified risk factors associated with the need of MV outside the OR. In our multi-institutional cohort, younger, smaller patients with increased preoperative 
TABLE 2. Prevalence of mechanical ventilation and reintubation in 8 STS benchmark operations

\begin{tabular}{|c|c|c|c|c|c|}
\hline \multirow[b]{2}{*}{ Variable } & \multirow[b]{2}{*}{ Total patients } & \multicolumn{2}{|c|}{ Extubated in operating room } & \multicolumn{2}{|c|}{ Arrived intubated in ICU } \\
\hline & & No. of patients & Reintubation & No. of patients & Reintubation \\
\hline VSD repair & 1330 & $303(22.8)$ & $4(1.3)$ & 1027 (77.2) & $41(4.0)$ \\
\hline TOF repair & 463 & $66(14.2)$ & $6(9.1)$ & $397(85.8)$ & $26(6.6)$ \\
\hline CAVC repair & 313 & $25(8.0)$ & $6(24.0)$ & $288(92.0)$ & $38(13.2)$ \\
\hline ASO & 692 & $22(3.2)$ & $8(36.4)$ & $670(96.8)$ & $44(6.6)$ \\
\hline ASO + VSD repair & 288 & $9(3.1)$ & $2(22.2)$ & 279 (96.9) & $33(11.8)$ \\
\hline Fontan & 1494 & $691(46.2)$ & $31(4.5)$ & $803(53.8)$ & $33(4.1)$ \\
\hline Truncus arteriosus repair & 212 & $10(4.7)$ & $3(30.0)$ & $202(95.3)$ & $37(18.3)$ \\
\hline Norwood operation & 1078 & $26(2.4)$ & $13(50.0)$ & 1052 (97.6) & $287(27.3)$ \\
\hline
\end{tabular}

Categorical variables are summarized as n (\%). ICU, Intensive care unit; $V S D$, ventricular septal defect; TOF, tetralogy of Fallot; $C A V C$, complete atrioventricular canal; ASO, arterial switch operation.

risk factors, patients associated with higher severity of illness scores, and patients undergoing high-complexity operations were associated with higher likelihood for MV outside the OR. Most of these factors are consistent with other singleinstitution studies in which younger and smaller patients with complex repairs required MV after cardiac surgery. ${ }^{1,2}$

A primary determinant of extubation success is the need for reintubation. Reintubation rates after pediatric cardiac surgery vary from $6 \%$ to $27 \%$ in the existing literature ${ }^{1,6-8}$; however, these studies were conducted among select patient populations in single institutions. In contrast, our study demonstrated a reintubation rate of $9 \%$ involving patients with varying surgical complexity and across centers of varied surgical volume. In our study, centers with a dedicated cardiac ICU were associated with lower odds of MV and lower odds of reintubation. It is possible that the multidisciplinary approach in the cardiac ICU caters to the postoperative needs of these patients better

TABLE 3. Risk factors associated with need for mechanical ventilation after pediatric heart surgery in multivariable models

\begin{tabular}{lllc}
\hline \multicolumn{1}{c}{ Variable } & Comparison & $\begin{array}{c}\text { Odds ratio } \\
(\mathbf{9 5} \% \mathbf{C I})\end{array}$ & $\begin{array}{c}\boldsymbol{P} \\
\text { value }\end{array}$ \\
\hline Male gender & Yes vs No & $1.01(0.93-1.10)$ & .87 \\
Age & 12-mo increase & $0.84(0.82-0.85)$ & $<.0001$ \\
Weight-for-age Z-score & 1 SD increase & $0.95(0.93-0.98)$ & $<.0001$ \\
Genetic disorder & Yes vs No & $1.26(1.13-1.41)$ & $<.0001$ \\
Low birth weight & Yes vs No & $2.11(1.59-2.75)$ & $<.0001$ \\
Pulmonary hypertension & Yes vs No & $1.77(1.30-2.40)$ & $<.0001$ \\
High-complexity operations & Yes vs No & $1.96(1.73-2.24)$ & $<.0001$ \\
Need for reoperation & Yes vs No & $1.55(1.24-1.91)$ & $<.0001$ \\
Acute lung injury & Yes vs No & $2.54(2.26-2.85)$ & $<.0001$ \\
PIM-2 score & 0.6-unit & $1.67(1.62-1.81)$ & $<.0001$ \\
& increase & & \\
Annual cardiac surgery & 100-case & $1.02(0.99-1.05)$ & .09 \\
$\quad$ per center & increase & & \\
Cardiac ICU & Yes vs No & $0.47(0.41-0.53)$ & $<.0001$ \\
\hline
\end{tabular}

High-complexity operations: Society of Thoracic Surgeons-European Association for Cardiothoracic Surgery surgical risk categories 4 and 5. CI, Confidence interval; $S D$, standard deviation; $P I M-2$, Pediatric Index of Mortality; $I C U$, intensive care unit. than the other ICU models. Better outcomes in the cardiac ICU also may be related to other factors, such as training and availability of personnel and use of standardized management protocols..$^{19,20}$

TABLE 4. Risk factors associated with need for reintubation after pediatric heart surgery in multivariable models

\begin{tabular}{|c|c|c|c|}
\hline Variable & Comparison & $\begin{array}{c}\text { Odds ratio } \\
(95 \% \text { CI })\end{array}$ & $\begin{array}{c}P \\
\text { value }\end{array}$ \\
\hline Male gender & Yes vs No & $1.04(0.93-1.16)$ & .55 \\
\hline Age & $\begin{array}{l}\text { 12-mo } \\
\text { increase }\end{array}$ & $0.89(0.86-0.92)$ & $<.0001$ \\
\hline Weight-for-age $Z$-score & $1 \mathrm{SD}$ increase & $0.92(0.88-0.96)$ & $<.0001$ \\
\hline Genetic disorder & Yes vs No & $1.45(1.30-1.62)$ & $<.0001$ \\
\hline Low birth weight & Yes vs No & $0.98(0.78-1.21)$ & .91 \\
\hline Pulmonary hypertension & Yes vs No & $1.31(1.08-1.63)$ & .005 \\
\hline High complexity operations & Yes vs No & $1.64(1.44-1.85)$ & $<.0001$ \\
\hline Need for reoperation & Yes vs No & $4.54(3.94-5.28)$ & $<.0001$ \\
\hline PIM-2 score & $\begin{array}{l}0.5 \text {-unit } \\
\text { increase }\end{array}$ & $1.17(1.14-1.21)$ & $<.0001$ \\
\hline Cardiac arrest & Yes vs No & $1.70(1.36-2.19)$ & $<.0001$ \\
\hline Acute lung injury & Yes vs No & $1.64(1.49-1.79)$ & $<.0001$ \\
\hline Chylothorax & Yes vs No & $2.22(1.64-3.05)$ & $<.0001$ \\
\hline Diaphragm paralysis & Yes vs No & $4.69(3.88-5.72)$ & $<.0001$ \\
\hline Brain hemorrhage & Yes vs No & $0.88(0.42-1.45)$ & .54 \\
\hline Renal failure & Yes vs No & $1.06(0.82-1.32)$ & .79 \\
\hline Seizures & Yes vs No & $1.83(1.41-2.32)$ & $<.0001$ \\
\hline Sepsis & Yes vs No & $2.35(1.47-3.34)$ & $<.0001$ \\
\hline Use of HFOV & Yes vs No & $27.17(17.73-48.18)$ & $<.0001$ \\
\hline Use of ECMO & Yes vs No & $0.96(0.75-1.17)$ & .65 \\
\hline $\begin{array}{l}\text { Extubated in operating } \\
\text { room }\end{array}$ & Yes vs No & $2.76(2.31-3.23)$ & $<.0001$ \\
\hline Duration of MV & 2-d increase & $1.04(1.02-1.06)$ & $<.0001$ \\
\hline $\begin{array}{l}\text { Annual cardiac surgery } \\
\text { per center }\end{array}$ & $\begin{array}{l}\text { 100-case } \\
\text { increase }\end{array}$ & $1.03(0.99-1.08)$ & .16 \\
\hline Cardiac ICU & Yes vs No & $0.78(0.66-0.90)$ & .005 \\
\hline
\end{tabular}

High-complexity operations: Society of Thoracic Surgeons-European Association for Cardiothoracic Surgery surgical risk categories 4 and 5. CI, Confidence interval; $P I M-2$, Pediatric Index of Mortality; HFOV, high-frequency oscillatory ventilation; $E C M O$, extracorporeal membrane oxygenation; $M V$, mechanical ventilation; $I C U$, intensive care unit. 
There are both advantages and disadvantages of continuing MV outside the OR after pediatric cardiac surgery. Sudden removal of positive pressure ventilation on extubation immediately after surgery in children with compromised hemodynamics can dramatically worsen the ongoing low cardiac output state and precipitate sudden cardiac arrest. Furthermore, extubation-related stress response causes a massive catecholamine surge that can initiate life-threatening arrhythmias or precipitate a pulmonary hypertensive crisis, thereby leading to sudden cardiovascular collapse. On the other hand, potential advantages of early extubation include less ventilatorassociated complications, such as pulmonary infections and atelectasis, less airway irritation, less barotrauma secondary to positive airway pressure ventilation, reduced parental stress, reduced requirements for sedatives, more rapid patient mobilization, and less resource utilization, decreased length of ICU and hospital stay, and reduced costs. $^{1-6}$

Our study has several potential limitations. This study is subject to the limitations of all observational analyses, including selection bias, residual confounding, and measurement error. Other limitations of the present study are related to the nature of the VPS dataset. Not all US pediatric hospitals participate in the VPS database. Nonetheless, the present report represents the most inclusive evaluation, with data from 62 pediatric heart centers. We were also limited to consideration of variables collected in the VPS database. Although we attempted to adjust for important patient confounders, other unmeasured confounders could have affected our analysis. As such, we could not evaluate or account for the potential impact of other variables (such as hospital structure and process of care measures, training or availability of ICU personnel, or nursing factors) on our evaluation of odds for MV. Due to database limitation, our study also lacked data on number of reintubations performed in the OR. Our database also lacks reasons for reintubations for the study patients.

Our study lacked data on certain key patient and treatment variables, such as $\mathrm{PaO}_{2}$ (partial pressure of oxygen in arterial blood), $\mathrm{PaCO}_{2}$ (partial pressure of carbon dioxide in arterial blood), $\mathrm{FiO}_{2}$ (fraction of inspired oxygen), $\mathrm{PaO}_{2} /$ $\mathrm{FiO}_{2}$ ratio, presence of focal versus diffuse lung disease, use of nitric oxide, and presence of air leak that could have been used in the multivariable modeling. Our study also lacked data on MV, such as plateau, mean, and end expiratory pressures, data on inotropes, and sedatives and neuromuscular blocking agents that could have potentially affected both need of MV and need for reintubation. Due to the retrospective, multi-institutional nature of this study, we did not consider the role of difficulties from mechanical ventilator weaning in the group with failed extubation. Due to the large sample size, some differences that are not clinically significant may appear to be statistically significant in univariable analysis; however, the effects of these variables were addressed in the multivariable analysis.

\section{CONCLUSIONS}

Large variations were demonstrated in clinical practices of MV following pediatric cardiac surgery among patients with varying surgical complexity and across centers with varied surgical volume. Our study establishes that approximately one-quarter of patients undergoing heart operations are extubated in the OR, whereas approximately three-quarters of patients are arriving intubated postoperatively in the ICU. In addition, approximately $9 \%$ of patients require reintubation after their initial extubation attempt. Both odds of MV and odds of reintubation after cardiac surgery are a function of patient characteristics, surgical risk category, and center volume. These data further suggest that extubation in the OR can be done successfully with a low complication rate. Using databases such as the VPS for clinical outcomes research may in the future decrease the cost of discovery and guide us in improving outcomes for critically ill patients.

\section{Conflict of Interest Statement}

Authors have nothing to disclose with regard to commercial support.

The authors thank the Office of Grants and Scientific Publications for their editorial assistance.

\section{References}

1. Harris KC, Holowachuk S, Pitfield S, Sanatani S, Froese N, Potts JE, et al. Should early extubation be the goal for children after congenital cardiac surgery? J Thorac Cardiovasc Surg. 2014;148:2642-7.

2. Howard F, Brown KL, Garside V, Walker I, Elliott MJ. Fast-track paediatric cardiac surgery: the feasibility and benefits of a protocol for uncomplicated cases. Eur J Cardiothorac Surg. 2010;37:193-6.

3. Davis S, Worley S, Mee RBB, Harrison AM. Factors associated with early extubation after cardiac surgery in young children. Pediatr Crit Care Med. 2004;5:63-8.

4. Vricella LA, Dearani JA, Gundry SR, Razzouk AJ, Brauer SD, Bailey LL. Ultra fast track in elective congenital cardiac surgery. Ann Thorac Surg. 2000;69: 865-71.

5. Laussen PC, Roth SJ. Fast tracking: efficiently and safely moving patients through the intensive care unit. Prog Pediatr Cardiol. 2003;18:149-58.

6. Gupta P, McDonald R, Gossett JM, Butt W, Shinkawa T, Imamura M, et al. A single center experience of extubation failure in infants undergoing the Norwood operation. Ann Thorac Surg. 2012;94:1262-8.

7. Gupta P, McDonald R, Goyal S, Gossett JM, Imamura M, Agarwal A, et al. Extubation failure in infants with shunt-dependent pulmonary blood flow and univentricular physiology. Cardiol Young. 2013;8:1-9.

8. Gupta P, Chow V, Gossett JM, Yeh JC, Roth SJ. Incidence, predictors and outcomes of extubation failure in children after orthotopic heart transplantation: a single-center experience. Pediatr Cardiol. 2015;36:300-7.

9. Mittnacht AJC, Thanjan M, Srivastava S, Joashi U, Bodian C, Hossain S, et al Extubation in the operating room after congenital heart surgery in children. J Thorac Cardiovasc Surg. 2008;136:88-93.

10. O'Brien SM, Clarke DR, Jacobs JP, Jacobs ML, Lacour-Gayet FG, Pizarro C, et al. An empirically based tool for analyzing mortality associated with congenital heart surgery. J Thorac Cardiovasc Surg. 2009;138:1139-53. 
11. Gupta P, Jacobs JP, Pasquali SK, Hill KD, Gaynor JW, O’Brien SM, et al. Epidemiology and outcomes following in-hospital cardiac arrest after pediatric cardiac surgery. Ann Thorac Surg. 2014;98:2138-44.

12. Welke KF, O'Brien SM, Peterson ED, Ungerleider RM, Jacobs ML, Jacobs JP. The complex relationship between pediatric cardiac surgical case volumes and mortality rates in a national clinical database. J Thorac Cardiovasc Surg. 2009; 137:1133-40.

13. Slater A, Shann F, Pearson G, for the PIM Study Group. PIM2: a revised version of the paediatric index of mortality. Intensive Care Med. 2003; 29:278-85.

14. Pollack MM, Patel KM, Ruttimann UE. PRISM III: an updated pediatric risk of mortality score. Crit Care Med. 1996;24:743-52.

15. Carpenter J, Bithell J. Bootstrap confidence intervals: when, which, what? A practical guide for medical statisticians. Stat Med. 2000;19:1141-64.

16. Austin PC. Balance diagnostics for comparing the distribution of baseline covariates between treatment groups in propensity-score matches sample. Stat Med. 2009;28:3083-107.
17. Kanter RK, Bove EL, Tobin JR, Zimmerman JJ. Prolonged mechanical ventilation of infants after open heart surgery. Crit Care Med. 1986;14: 211-4.

18. Harrison AM, Cox AC, Davis S, Piedmonte M, Drummond-Webb JJ, Mee RB. Failed extubation after cardiac surgery in young children: prevalence, pathogenesis, and risk factors. Pediatr Crit Care Med. 2002:3:148-52.

19. Burstein DS, Jacobs JP, Li JS, Sheng S, O’Brien SM, Rossi AF, et al. Care models and associated outcomes in congenital heart surgery. Pediatrics. 2011;127: e1482-9.

20. Gupta P, Beam BW, Noel TR, Dvorchik I, Yin H, Simsic JM, et al. Impact of pre-operative location on outcomes in congenital heart surgery. Ann Thorac Surg. 2014;98:896-903.

Key Words: mechanical ventilation, pediatric cardiac surgery, reintubation, surgical complexity, center volume

\title{
EDITORIAL COMMENTARY
}

\section{Can multicenter registries determine the optimal timing of extubation after congenital heart surgery?}

\author{
Sarah Tabbutt, MD, PhD
}

\footnotetext{
From the Divisions of Cardiology and the Critical Care Medicine, Department of Pediatrics, University of California San Francisco Benioff Children's Hospital, San Francisco, Calif.

Disclosures: Author has nothing to disclose with regard to commercial support.

Received for publication Oct 23, 2015; accepted for publication Oct 24, 2015.

Address for reprints: Sarah Tabbutt, MD, PhD, University of California San Francisco Benioff Children's Hospital, Mission Hall, Box 0106, 550 16th St, 5th floor, San Francisco, CA 94143 San Francisco, CA 94132 (E-mail: tabbutts@peds.ucsf.edu).

J Thorac Cardiovasc Surg 2016;151:458-9

$0022-5223 / \$ 36.00$

Copyright (c) 2016 by The American Association for Thoracic Surgery

http://dx.doi.org/10.1016/j.jtcvs.2015.10.088
}

The length of time that a patient is on mechanical ventilation has been shown to be associated with both intensive care unit (ICU) and hospital length of stay after congenital heart surgery, including surgery involving complex palliations, such as the Norwood procedure. ${ }^{1,2}$ Although this relationship is not always causal, experts recommend that extubation be performed as early as reasonably possible, ${ }^{3,4}$ to limit exposure to morbidities associated with prolonged ventilation, as well as therapies required with ventilation, such as analgesia, sedation, and use of invasive catheters.

Questions remain as to which patients can be safely extubated early in the postoperative course and what factors might predict subsequent failure of unassisted respiration. Although only a small percentage of patients require reintubation, the associated morbidity should be avoided.

Gupta and colleagues ${ }^{5}$ conducted a retrospective analysis of prospectively collected data to determine factors

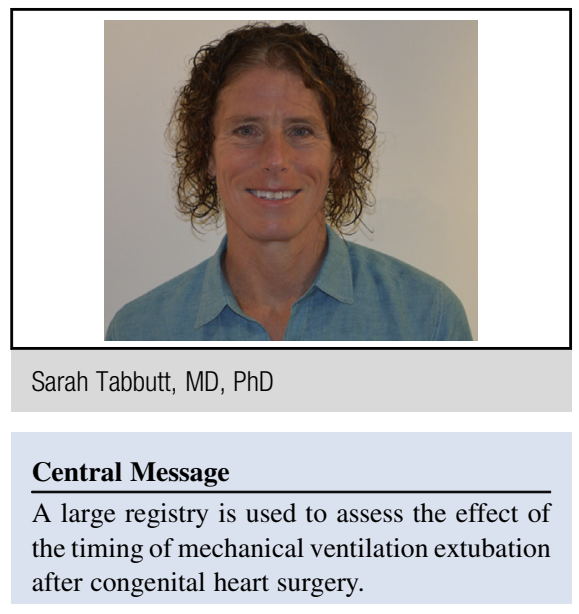

See Article page 451.

that affect ICU mechanical ventilation and reintubation after pediatric congenital heart surgery, using the Virtual PICU Systems (pediatric ICU; Los Angeles, Calif) database. This analysis represents a sizable number of patients $(27,298)$ from a large number of centers $(62)$. Independent patient risk factors identified for mechanical ventilation in the ICU included: younger age; lower weight; genetic disorder; pulmonary hypertension; complex operations for patients in congenital heart surgery mortality categories 4 or 5 (Society of Thoracic 


\section{APPENDIX 1. SUPPLEMENTARY ONLINE CONTENT}

Gupta P, Rettiganti M, Gossett JM, Yeh JC, Jeffries HE, Rice TB, Wetzel RC. Risk factors for mechanical ventilation and reintubation after pediatric heart surgery.

\section{TABLE OF CONTENTS}

Figure E1. Center Volume and proportion of patients receiving mechanical ventilation for the VPS study center... 459.e2
Table E1. Propensity model for risk factors associated with need for mechanical ventilation based on location of the patient ..459.e2

Table E2. Propensity model for risk factors associated with need for reintubation based on location of the patient 459.e3

Table E3. Study outcomes based on location of patients after cardiac surgery 459.e3 


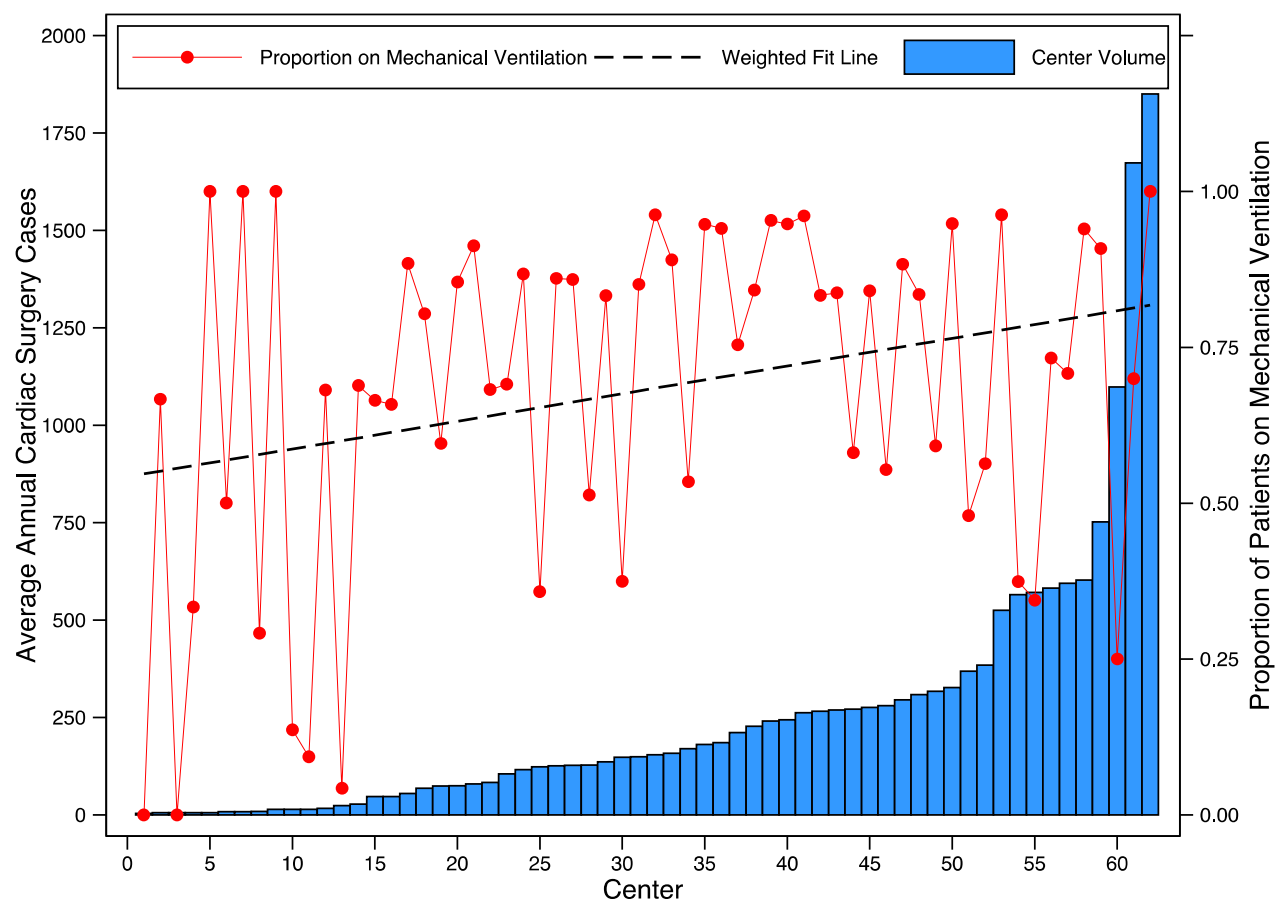

FIGURE E1. Center volume and proportion of patients receiving mechanical ventilation for the Virtual PICU Systems, LLC, study centers.

TABLE E1. Propensity model for risk factors associated with need for mechanical ventilation based on location of the patient

\begin{tabular}{|c|c|c|c|c|c|c|}
\hline \multirow[b]{2}{*}{ Variable } & \multicolumn{3}{|c|}{ Unmatched } & \multicolumn{3}{|c|}{ Matched } \\
\hline & $\begin{array}{r}\text { Cardiac ICU } \\
(\mathrm{n}=16,767) \\
\end{array}$ & $\begin{array}{c}\text { Other ICU } \\
(n=10,631)\end{array}$ & Std Diff & $\begin{array}{c}\text { Cardiac } \\
\text { ICU }(\mathbf{n}=\mathbf{3 6 3 4})\end{array}$ & $\begin{array}{l}\text { Other ICU } \\
(n=3634)\end{array}$ & Std Diff \\
\hline Age at surgery (mo) & $36.6(54.8)$ & $38.8(56.6)$ & 0.04 & $37.3(56.7)$ & $35.1(53.7)$ & 0.03 \\
\hline Male gender & $9205(54.9 \%)$ & $5891(55.4 \%)$ & 0.01 & $2022(55.6 \%)$ & $2038(56.1 \%)$ & 0.008 \\
\hline Weight-for-age Z-score & $-0.9(1.4)$ & $-0.9(1.4)$ & 0.001 & $-0.9(1.4)$ & $-1.0(1.4)$ & 0.01 \\
\hline Developmental disorder & $471(2.8 \%)$ & $315(3 \%)$ & 0.01 & $109(3 \%)$ & $90(2.5 \%)$ & 0.03 \\
\hline Failure to thrive & $1601(9.5 \%)$ & $839(7.9 \%)$ & 0.05 & $210(5.8 \%)$ & $232(6.4 \%)$ & 0.02 \\
\hline Genetic disorder & $3039(18.1 \%)$ & $1906(17.9 \%)$ & 0.005 & $659(18.1 \%)$ & $656(18.1 \%)$ & 0.002 \\
\hline Low birth weight & $1008(6 \%)$ & $428(4 \%)$ & 0.09 & $148(4.1 \%)$ & $145(4 \%)$ & 0.004 \\
\hline Acute Lung Injury & $3951(23.6 \%)$ & $3721(35 \%)$ & 0.25 & $1407(38.7 \%)$ & $1467(40.4 \%)$ & 0.03 \\
\hline Pulmonary hypertension & $686(4.1 \%)$ & $710(6.7 \%)$ & 0.11 & $189(5.2 \%)$ & $210(5.8 \%)$ & 0.02 \\
\hline PIM-2 score & $-3.8(1.3)$ & $-3.8(1.3)$ & 0.05 & $-3.7(1.3)$ & $-3.6(1.1)$ & 0.02 \\
\hline High-complexity operations & $4413(26.3 \%)$ & $2617(24.6 \%)$ & 0.03 & $941(25.9 \%)$ & $1027(28.3 \%)$ & 0.05 \\
\hline Heart transplantation & $443(2.6 \%)$ & $57(0.5 \%)$ & 0.16 & $69(1.9 \%)$ & $54(1.5 \%)$ & 0.03 \\
\hline Need for reoperation & $2242(13.4 \%)$ & $1553(14.6 \%)$ & 0.03 & $601(16.5 \%)$ & $693(19.1 \%)$ & 0.06 \\
\hline $\begin{array}{l}\text { Annual cardiac surgery per } \\
\text { center }\end{array}$ & $442(146)$ & $179(110)$ & 2.02 & $277(30)$ & $273(48)$ & 0.09 \\
\hline
\end{tabular}

ICU, Intensive care unit; PIM-2, Pediatric Index of Mortality; Std Diff, standardized difference. 
TABLE E2. Propensity model for risk factors associated with need for reintubation based on location of the patient

\begin{tabular}{|c|c|c|c|c|c|c|}
\hline \multirow[b]{2}{*}{ Variable } & \multicolumn{3}{|c|}{ Unmatched } & \multicolumn{3}{|c|}{ Matched } \\
\hline & $\begin{array}{l}\text { Cardiac ICU } \\
(\mathrm{n}=16,767)\end{array}$ & $\begin{array}{c}\text { Other ICU } \\
(n=10,631)\end{array}$ & Std Diff & $\begin{array}{c}\text { Cardiac } \\
\text { ICU }(\mathbf{n}=\mathbf{3 6 3 8})\end{array}$ & $\begin{array}{l}\text { Other ICU } \\
(\mathbf{n}=\mathbf{3 6 3 8})\end{array}$ & Std Diff \\
\hline Age at surgery (mo) & $36.6(54.8)$ & $38.8(56.6)$ & 0.03 & $36.5(55.4)$ & $36.7(54.8)$ & 0.004 \\
\hline Male gender & $9205(54.9 \%)$ & $5891(55.4 \%)$ & 0.01 & $2021(55.1 \%)$ & $2045(55.8 \%)$ & 0.01 \\
\hline Weight-for-age $Z$-score & $-0.9(1.4)$ & $-0.96(1.5)$ & 0.001 & $-0.99(1.4)$ & $-1.00(1.5)$ & 0.006 \\
\hline Development disorder & $471(2.8 \%)$ & $315(3 \%)$ & 0.009 & $101(2.8 \%)$ & $89(2.4 \%)$ & 0.02 \\
\hline Failure to thrive & $1601(9.5 \%)$ & $839(7.9 \%)$ & 0.05 & $237(6.5 \%)$ & $232(6.3 \%)$ & 0.01 \\
\hline Genetic disorder & $3039(18.1 \%)$ & $1906(17.9 \%)$ & 0.005 & $659(18 \%)$ & $662(18.1 \%)$ & 0.003 \\
\hline Low birth weight & $1008(6 \%)$ & $428(4 \%)$ & 0.09 & $142(3.9 \%)$ & $134(3.7 \%)$ & 0.01 \\
\hline Pulmonary hypertension & $686(4.1 \%)$ & $710(6.7 \%)$ & 0.11 & $177(4.8 \%)$ & $192(5.2 \%)$ & 0.02 \\
\hline PIM-2 score & $-3.8(1.3)$ & $-3.88(1.4)$ & 0.06 & $-3.74(1.2)$ & $-3.66(1.5)$ & 0.06 \\
\hline Arrhythmia & $3056(18.2 \%)$ & $1547(14.6 \%)$ & 0.09 & $633(17.3 \%)$ & $613(16.7 \%)$ & 0.009 \\
\hline Acute lung injury & $3951(23.6 \%)$ & $3721(35 \%)$ & 0.25 & $1418(38.7 \%)$ & $1473(40.2 \%)$ & 0.03 \\
\hline Cardiac arrest & $435(2.6 \%)$ & $251(2.4 \%)$ & 0.01 & $68(1.9 \%)$ & $75(2 \%)$ & 0.01 \\
\hline Chylothorax & $229(1.4 \%)$ & $114(1.1 \%)$ & 0.02 & $16(0.4 \%)$ & $18(0.5 \%)$ & 0.004 \\
\hline Diaphragm paralysis & $407(2.4 \%)$ & $183(1.7 \%)$ & 0.04 & $67(1.8 \%)$ & $59(1.6 \%)$ & 0.01 \\
\hline Renal failure & $584(3.5 \%)$ & $221(2.1 \%)$ & 0.08 & $69(1.9 \%)$ & $80(2.2 \%)$ & 0.02 \\
\hline Seizures & $499(3 \%)$ & $247(2.3 \%)$ & 0.04 & $76(2.1 \%)$ & $83(2.3 \%)$ & 0.01 \\
\hline Sepsis & $177(1.1 \%)$ & $105(1 \%)$ & 0.007 & $21(0.6 \%)$ & $27(0.7 \%)$ & 0.01 \\
\hline Brain hemorrhage & $91(0.5 \%)$ & $38(0.4 \%)$ & 0.02 & $10(0.3 \%)$ & $15(0.4 \%)$ & 0.02 \\
\hline High complexity operations & $4413(26.3 \%)$ & $2617(24.6 \%)$ & 0.04 & $940(25.6 \%)$ & $1006(27.4 \%)$ & 0.03 \\
\hline Need for reoperation & $2242(13.4 \%)$ & $1553(14.6 \%)$ & 0.03 & $568(15.5 \%)$ & $660(18 \%)$ & 0.07 \\
\hline Heart transplantation & $443(2.6 \%)$ & $57(0.5 \%)$ & 0.17 & $60(1.6 \%)$ & $50(1.4 \%)$ & 0.02 \\
\hline Use of ECMO & $588(3.5 \%)$ & $380(3.6 \%)$ & 0.003 & $150(4.1 \%)$ & $146(4 \%)$ & 0.002 \\
\hline Use of HFOV & $79(0.5 \%)$ & $109(1 \%)$ & 0.06 & $20(0.5 \%)$ & $23(0.6 \%)$ & 0.007 \\
\hline $\begin{array}{l}\text { Duration of MV before } \\
\text { reintubation }\end{array}$ & $3.73(9.5)$ & $3.67(9.1)$ & 0.007 & $3.89(7.2)$ & $3.92(8.7)$ & 0.003 \\
\hline Extubated in OR & $4706(28.1 \%)$ & $2104(19.8 \%)$ & 0.19 & $667(18.2 \%)$ & $568(15.5 \%)$ & 0.07 \\
\hline $\begin{array}{l}\text { Annual cardiac surgery per } \\
\text { center }\end{array}$ & 442 (146) & $179(110)$ & 2.02 & $276(30)$ & $272(50)$ & 0.09 \\
\hline
\end{tabular}

$\overline{I C U}$, Intensive care unit; $P I M-2$, Pediatric Index of Mortality; $E C M O$, extracorporeal membrane oxygenation; $H F O V$, high-frequency oscillatory ventilation; $M V$, mechanical ventilation; $O R$, operating room; Std Diff, standardized difference.

TABLE E3. Study outcomes based on location of patients after cardiac surgery

\begin{tabular}{|c|c|c|c|c|c|c|}
\hline \multirow[b]{2}{*}{ Variable } & \multicolumn{3}{|c|}{ Unmatched } & \multicolumn{3}{|c|}{ Matched $*$} \\
\hline & $\begin{array}{l}\text { Cardiac ICU } \\
(\mathrm{n}=16,767)\end{array}$ & $\begin{array}{c}\text { Other ICU } \\
(n=10,631)\end{array}$ & $P$ value & $\begin{array}{c}\text { Cardiac ICU } \\
(\mathrm{n}=\mathbf{3 6 3 4})\end{array}$ & $\begin{array}{l}\text { Other ICU } \\
(\mathbf{n}=\mathbf{3 6 3 4})\end{array}$ & $P$ value \\
\hline \multirow[t]{2}{*}{$\begin{array}{l}\text { Need for mechanical } \\
\text { ventilation }\end{array}$} & $12,061(71.9 \%)$ & $8527(80.2 \%)$ & $<.0001$ & $2846(78.3 \%)$ & $3199(88.0 \%)$ & $<.0001$ \\
\hline & $\begin{array}{l}\text { Cardiac ICU } \\
(n=16,767) \\
\end{array}$ & $\begin{array}{c}\begin{array}{c}\text { Other ICU } \\
(n=10,631)\end{array} \\
\end{array}$ & $P$ value & $\begin{array}{c}\text { Cardiac ICU } \\
(n=3638) \\
\end{array}$ & $\begin{array}{l}\text { Other ICU } \\
(n=3638) \\
\end{array}$ & $P$ value \\
\hline Need for reintubation & $1409(8.4 \%)$ & $1040(9.8 \%)$ & $<.0001$ & $263(7.2 \%)$ & $361(9.9 \%)$ & $<.0001$ \\
\hline
\end{tabular}

